\title{
PREVALENCE OF HYPERURICEMIA AND ITS ASSOCIATION WITH SOCIODEMOGRAPHY AMONG HYPERTENSIVE PATIENTS AT BIRAT MEDICAL COLLEGE TEACHING HOSPITAL
}

\author{
Ram Kumar Mehta ${ }^{1 *}$, Puru Koirala², Ram L. Mallick', Surya Parajuli ${ }^{4}$, Rajneesh Jha ${ }^{5}$
}

\section{Affiliation}

1. Lecturer, Department of Internal Medicine, Birat Medical College \& Teaching Hospital, Nepal.

2. Associate Professor, Department of Internal Medicine, Birat Medical College and Teaching Hospital, Nepal.

3. Assistant Professor, Department of Biochemistry, Birat Medical College and Teaching Hospital, Nepal.

4. Assistant Professor, Department of Community Medicine, Birat Medical College and Teaching Hospital, Nepal.

5. Assistant Professor, Department of Internal Medicine, Birat Medical College and Teaching Hospital, Nepal.

\section{ARTICLE INFO}

Received : 09 March, 2021

Accepted : 04 April, 2021

Published : 15 June, 2021

(c) Authors retain copyright and grant the journal right of first publication with the work simultaneously licensed under Creative Commons Attribution License CC - BY 4.0 that allows others to share the work with an acknowledgment of the work's authorship and initial publication in this journal.

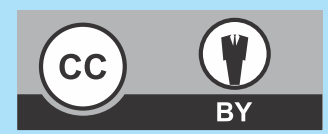

\section{ORA 240}

DOI: https://doi.org/10.3126/bjhs.v6i1.37643

\section{* Corresponding Author}

Dr. Ram Kumar Mehta Lecturer

Department of Internal Medicine

Birat Medical College and Teaching Hospital, Nepal Email:mehtark0123@gmail.com

ORCID: https://orcid.org/0000-0002-1759-9852

\section{Citation}

Ram Kumar Mehta, Puru Koirala, Ram L. Mallick, Surya Parajuli, Rajneesh Jha. Prevalence of Hyperuricemia and its Association with Sociodemography among Hypertensive Patients at Birat Medical College Teaching Hospital. BJHS 2021;6(1)14. 1388 - 1391.

\section{ABSTRACT}

\section{Introduction}

Hypertension is the most common cardiovascular diseases. In only 5-10\% of hypertensive patients, underlying cause can be identified (secondary hypertension). Serum uric acid is thought to play a pathogenic role in development of hypertension and is also a commonly associated condition in patients with hypertension. Management of hyperuricemia will ultimately help in reducing cardiovascular morbidity and mortality.

\section{Objectives}

To determine the prevalence of hyperuricemia among hypertensive patients attending Birat Medical College Teaching Hospital and also to find association between hyperuricemia and socio-demographic variables.

\section{Methodology}

This was a descriptive hospital based cross-sectional study conducted in 168 hypertensive patients at Birat Medical College Teaching Hospital, Nepal for a period of 6 months from $1^{\text {st }}$ September 2020 to $28^{\text {th }}$ February 2021. Sociodemographic variables were recorded and serum uric acid level was obtained based on the pre-structured questionnaires. Data were analyzed by Statistical Package for the Social Sciences version 20 (SPSS 20).

\section{Result}

Prevalence of hyperuricemia was 42 (25\%) among hypertensive patients with more prevalent in male 33 $(30.8 \%)$ than female 9 (14.8\%). Hyperuricemia was more prevalent in patients having higher $\mathrm{BMI}$ and patients aged more than 60 years i.e. $38(34.5 \%)$ and $25(41.7 \%)$ respectively. It was more prevalent among patients with hypertension for more than 15 years 10 (41.7\%) and non-vegetarian $33(25.8 \%)$. Hyperuricemia was significantly associated with those aged more than 60 years $(p=0.002)$ and BMI $>25 \mathrm{~kg} / \mathrm{m}^{2}(p=0.002)$.

\section{Conclusion}

Hyperuricemia was common associated condition among hypertensive patients. Hyperuricemia is mainly associated with male gender, non-vegetarian and patients with longer duration of hypertension. Similarly, it was strongly associated with older age and patients having higher BMI. Monitoring of serum uric acid and management of hyperuricemia might be helpful in management of hypertension and thus decreasing cardiovascular morbidity and mortality.

\section{KEY WORDS}

$B M I$, hypertension, hyperuricemia. 


\section{INTRODUCTION}

Hypertension is one of the leading causes of the global burden of disease. It is the most common form of cardiovascular disease. The prevalence of hypertension increases with aging, which in turn increases morbidity and mortality through various events such as coronary heart disease (CHD), congestive heart failure (CHF), ischemic and hemorrhagic stroke, renal failure, and peripheral arterial disease. ${ }^{2}$ In only $5-10 \%$ of hypertensive patients, underlying cause can be identified (secondary hypertension), 90-95\% of hypertensive patients are diagnosed as having essential hypertension. ${ }^{3}$

Uric acid largely exists as urate at neutral $\mathrm{pH}$ which is the end product of purine metabolism in humans. The serum urate level depends on dietary purines, the degradation of endogenous purines and the renal and intestinal excretion of urate. ${ }^{4}$

Different studies have demonstrated the association between serum uric acid level and hypertension. Hyperuricemia is an independent risk factor for developing hypertension. ${ }^{5}$ Mechanism of hyperuricemia induced hypertension can be divided into 2 phases: an initial phase that is driven by uric acid per se and mediated by oxidative stress, inflammation, endothelial dysfunction, and activation of the reninangiotensin-aldosterone system, and a later phase that is driven by arterial wall hypertrophy and renal microvascular changes and interstitial inflammation. ${ }^{6.7}$

Prevalence of hyperuricemia in hypertensive Nepalese patients was observed to be $28.8 \% .^{8}$ Serum uric acid concentrations increases with age and further increases after menopause in women. ${ }^{9}$ There are various factors such as metabolic syndrome, diabetes mellitus, chronic kidney disease, obesity, alcohol consumption, salt intake and fluid volume status etc. which can alter serum uric acid level. ${ }^{10}$ Presence of hyperuricemia in patients with hypertension further increases cardiovascular morbidity and mortality. ${ }^{11}$

As hyperuricemia is an independent risk factor for the development of hypertension. Early detection of hyperuricemia will be valuable in management of hypertension. Thus, this study aimed to determine the prevalence of hyperuricemia and to assess its association with sociodemography among hypertensive Nepalese patients residing in this region.

\section{METHODOLOGY}

This is a descriptive cross sectional study conducted in Department of Internal Medicine at Birat Medical College Teaching Hospital, Nepal for a period of 6 months from $1^{\text {st }}$ September 2020 to $28^{\text {th }}$ February 2021. A total of 168 patients with hypertension (Age $>15$ years) were enrolled based on convenient sampling technique. Prior to the study, ethical clearance was obtained from institutional review committee (IRC-PA-067/2077-78). Written consent was obtained from all hypertensive patients aged more than 15 years and willing to be enrolled in study. Patients with age less than 15 years, gout, chronic alcoholism, diabetes mellitus, chronic kidney disease, pregnancy, leukemia, lymphoma, carcinoma, anti-cancer therapy and who denied to give written consent were excluded from the study. All patients who met inclusion criteria were sent for serum uric acid assay in department of Biochemistry. All participants were asked relevant questions to note socio-demographic information based on pre-structured questionnaires. Patients were categorized according age group in years $(<30,30-45$, $45-60$ and $>60$ ). Similarly body mass index (BMI) was calculated and all patients were categorized into $\mathrm{BMI}<25$ and $>25 \mathrm{~kg} / \mathrm{m}^{2}$.

Hypertension was designated to patient who were already diagnosed by physician or according to blood pressure readings by European Society of Cardiology(ESC) and European Society of Hypertension definitions(ESH). ${ }^{12}$ Patient who were already under antihypertensive drugs or with blood pressure more than $140 / 90 \mathrm{mmHg}$ were enrolled in the study. Serum uric acid level greater than $6.0 \mathrm{mg} / \mathrm{dL}$ were considered as hyperuricemia. ${ }^{13}$

Data were entered and analyzed using the Statistical Package for the Social Sciences (SPSS) version 20.0 for Windows. Demographic variables were analyzed using descriptive statistics and association between sociodemography and hyperuricemia were analyzed using bivariate analysis and binary logistic regression.

\section{RESULTS}

During the period of six months 168 hypertensive patients who met inclusion criteria were enrolled in this study. Out of which $107(63.7 \%)$ were male and $61(36.3 \%)$ were female. Mean age of participants was $54.95 \pm 12.84$ years. Mean systolic and diastolic blood pressure was $146.01 \pm 9.49$ $\mathrm{mmHg}$ and $89.52 \pm 7.08 \mathrm{mmHg}$ respectively. Mean serum uric acid level was $5.39 \pm 1.32 \mathrm{mg} / \mathrm{dl}$. Male participants had slight higher mean serum uric level than female i.e. 5.61 \pm 1.4 $\mathrm{mg} / \mathrm{dl}$ and $5.01 \pm 1.07 \mathrm{mg} / \mathrm{dl}$ respectively. Most of them $77(45.8 \%)$ belong to aged $45-60$ years. Majority of participants were non-vegetarian and had high BMI i.e. $128(76.2 \%)$ and $110(65.5 \%)$ respectively. (Table 1 )

\begin{tabular}{|c|c|c|c|}
\hline Variable & Male & Female & Total \\
\hline Frequency (n) & $107(63.7 \%)$ & $61(36.3 \%)$ & $168(100 \%)$ \\
\hline \multicolumn{4}{|l|}{ Age Group (years) } \\
\hline$<30$ & $3(2.8 \%)$ & $2(3.3 \%)$ & $5(3 \%)$ \\
\hline $30-45$ & $16(15 \%)$ & $10(16.4 \%)$ & $26(15.5 \%)$ \\
\hline $45-60$ & $47(43.9 \%)$ & $30(49.2 \%)$ & $77(45.8 \%)$ \\
\hline$>60$ & $41(38.3 \%)$ & $19(31.1 \%)$ & $60(35.7 \%)$ \\
\hline \multicolumn{4}{|l|}{ Religion } \\
\hline Hindu & $103(96.3 \%)$ & $58(95.1 \%)$ & $161(95.8 \%)$ \\
\hline Muslim & $2(1.9 \%)$ & $2(3.3 \%)$ & $4(2.4 \%)$ \\
\hline Buddhist & $2(1.9 \%)$ & $1(1.6 \%)$ & $3(1.8 \%)$ \\
\hline \multicolumn{4}{|l|}{ Education } \\
\hline No formal & $35(32.7 \%)$ & $42(68.9 \%)$ & $77(45.8 \%)$ \\
\hline Primary & $12(11.2 \%)$ & $8(13.1 \%)$ & $20(11.9 \%)$ \\
\hline Secondary & $24(22.4 \%)$ & $8(13.1 \%)$ & $32(19.1 \%)$ \\
\hline University & $36(33.6 \%)$ & $3(4.9 \%)$ & $39(23.2 \%)$ \\
\hline \multicolumn{4}{|l|}{ Diet } \\
\hline Vegetarian & $15(14 \%)$ & $25(41 \%)$ & $40(23.8 \%)$ \\
\hline Non vegetarian & $92(86 \%)$ & $36(59 \%)$ & $128(76.2 \%)$ \\
\hline \multicolumn{4}{|l|}{ Smoking } \\
\hline Current smoker & $45(42.1 \%)$ & $2(3.3 \%)$ & $47(28 \%)$ \\
\hline Ex-smoker & $20(18.7 \%)$ & $7(11.5 \%)$ & $27(16 \%)$ \\
\hline Non-smoker & $42(39.3 \%)$ & $52(85.2 \%)$ & $94(56 \%)$ \\
\hline \multicolumn{4}{|l|}{ BMI* $\left(\mathrm{kg} / \mathrm{m}^{2}\right)$} \\
\hline$<25$ & $19(17.8 \%)$ & $39(63.9 \%)$ & $58(34.5 \%)$ \\
\hline$>25$ & $88(82.2 \%)$ & $22(36.1 \%)$ & $110(65.5 \%)$ \\
\hline
\end{tabular}

*BMI: Body Mass Index (calculated as Weight in Kg /Height in meter ${ }^{2}$ )

The prevalence of hyperuricemia among hypertensive patients was $42(25 \%)$. Similarly, prevalence of hyperuricemia 
among male was 33(30.8\%) and female was 9(14.8\%). Hyperuricemia was most common among the patients of age group more than 60 years i.e. 25(41.7\%). Hyperuricemia was more prevalent among non vegetarian and patients having higher BMI i.e. 33(25.8\%) and 38(34.5\%) respectively. (Table 2 )

\begin{tabular}{|c|c|c|}
\hline Variable & Number (n) & Percentage (\%) \\
\hline Overall & 42 & 25 \\
\hline Male & 33 & 30.8 \\
\hline Female & 9 & 14.8 \\
\hline \multicolumn{3}{|l|}{ Age Group (years) } \\
\hline$<30$ & 2 & 40 \\
\hline $30-45$ & 1 & 3.8 \\
\hline $45-60$ & 14 & 18.2 \\
\hline$>60$ & 25 & 41.7 \\
\hline \multicolumn{3}{|l|}{$\mathrm{BMI}\left(\mathrm{kg} / \mathrm{m}^{2}\right)$} \\
\hline$<25$ & 4 & 6.9 \\
\hline$>25$ & 38 & 34.5 \\
\hline \multicolumn{3}{|l|}{ Diet } \\
\hline Vegetarian & 9 & 22.5 \\
\hline Non vegetarian & 33 & 25.8 \\
\hline \multicolumn{3}{|l|}{$\begin{array}{l}\text { Duration of } \\
\text { Hypertension (years) }\end{array}$} \\
\hline $0-5$ & 10 & 15.9 \\
\hline $5-10$ & 11 & 22.9 \\
\hline $10-15$ & 11 & 33.3 \\
\hline$>15$ & 10 & 41.7 \\
\hline
\end{tabular}

Hyperuricemia was more common among male hypertensive patients but it was not statistically significant $(p=0.205)$. This study showed significant association between hyperuricemia and older age group $(p=0.002)$, high BMI $(p=0.002)$ and smoking $(p=0.018)$. (Table 3)

\begin{tabular}{|c|c|c|c|c|}
\hline \multirow[t]{2}{*}{ Variable } & \multicolumn{2}{|c|}{ Hyperuricemia } & \multirow[t]{2}{*}{ Odds ratio $(95 \% \mathrm{Cl})$} & \multirow[t]{2}{*}{$p$ value } \\
\hline & Number (n) & Percentage (\%) & & \\
\hline \multicolumn{5}{|l|}{ Gender } \\
\hline Male & 33 & 78.6 & $1.926(0.699-5.308)$ & 0.205 \\
\hline Female & 9 & 21.4 & & \\
\hline \multicolumn{5}{|l|}{ Age Group } \\
\hline$<30$ & 2 & 4.8 & & \\
\hline $30-45$ & 1 & 2.4 & & \\
\hline $45-60$ & 14 & 33.3 & & \\
\hline$>60$ & 25 & 59.5 & $2.364(1.372-4.071)$ & 0.002 \\
\hline \multicolumn{5}{|l|}{ Religion } \\
\hline Hindu & 39 & 92.8 & $1.739(0.689-4.40)$ & 0.243 \\
\hline Muslim & 1 & 2.4 & & \\
\hline Buddhist & 2 & 4.8 & & \\
\hline \multicolumn{5}{|l|}{ Education } \\
\hline No Formal & 21 & 50 & $0.915(0.688-1.217)$ & 0.542 \\
\hline Primary & 4 & 9.5 & & \\
\hline Secondary & 9 & 21.4 & & \\
\hline University & 8 & 19 & & \\
\hline \multicolumn{5}{|l|}{ BMI } \\
\hline$<25$ & 4 & 9.5 & & \\
\hline$>25$ & 38 & 90.5 & $6.550(1.952-21.976)$ & 0.002 \\
\hline \multicolumn{5}{|l|}{ Diet } \\
\hline Vegetarian & 9 & 21.4 & & \\
\hline Non-vegetarian & 33 & 78.6 & $0.989(0.352-2.774)$ & 0.983 \\
\hline \multicolumn{5}{|l|}{ Smoking } \\
\hline Current smoker & 18 & 42.9 & $0.622(0.419-0.922)$ & 0.018 \\
\hline Ex-smoker & 6 & 14.3 & & \\
\hline Non-smoker & 18 & 42.9 & & \\
\hline
\end{tabular}

\section{DISCUSSION}

Hyperuricemia is one of the important associated conditions in patients with hypertension. Various studies had shown association between hyperuricemia and cardiovascular diseases, including coronary heart disease, stroke, congestive heart failure, arterial hypertension and atrial fibrillation. ${ }^{14}$

Majority of the participants in our study were male with male to female ratio of $1.7: 1$ which is similar to the study done by Feig et al. ${ }^{15}$ In our study, majority of the patients were non vegetarian (76.2\%) and about $2 / 3^{\text {rd }}$ of the patients were having higher BMI (65.5\%). Consumption of western style diets which include high calorie foods with increased carbohydrate, fat, red meat consumption, low fiber content and reduced physical activity have contributed to the increased prevalence of obesity and metabolic syndrome. ${ }^{16}$ In this study, mean systolic and diastolic blood pressure of the participants were $146.01 \pm 9.49 \mathrm{mmHg}$ and $89.52 \pm 7.08$ $\mathrm{mmHg}$ which is similar to a study conducted in different region of Nepal. In our study, we found mean uric acid level to be $5.39 \pm 1.32 \mathrm{mg} / \mathrm{dl}$ which is also similar to study conducted by Poudel et al.

Prevalence of hyperuricemia among hypertensive patients in our study was $25 \%$ with $30.8 \%$ in male and $14.8 \%$ in female participants which is similar to study conducted in another region of Nepal. ${ }^{8}$ This is slight higher than study conducted in Bangladeshi adults which showed prevalence of hyperuricemia to be $9.3 \%$ with $8.4 \%$ in male and $10.2 \%$ in female participants. ${ }^{17}$ Hyperuricemia was more common in patients with higher age i.e. $41.7 \%$ in more than 60 years age group. This is in accordance to a report from a tertiary center of Nepal. ${ }^{9}$ In contrast to this study done by Lin et al revealed to be highest prevalence among patients of younger age group. ${ }^{18}$ This study showed increased prevalence of hyperuricemia in patient with longer duration of hypertension i.e. $41.7 \%$ in participants having hypertension for more than 15 years. This could be due to use of antihypertensive drugs especially diuretics. Hyperuricemia was more prevalent in participant having BMI more than $25 \mathrm{~kg} / \mathrm{m}^{2}$ (34.5\%) which is similar to study conducted by Ali et al. ${ }^{17}$ Increasing prevalence of hyperuricemia in obese patients could be due to its overproduction with a decrease in urinary urate excretion and clearance. ${ }^{19}$

We found clear association between certain sociodemographic variables and risk factors with hyperuricemia in hypertensive patients. For instance, our study revealed significant association between hyperuricemia and increasing age i.e. more than 60 years age group $(p=0.002)$. This is consistent with study done by Yadav et al which revealed prevalence of hyperuricemia to be $56.25 \%$ among age group $>65$ years. ${ }^{9}$ Increasing prevalence of hyperuricemia with age might be due to impaired renal function, use of diuretics and higher prevalence of hypertension in elderly patients. ${ }^{9}$ This study showed significant association between hyperuricemia and patients with $\mathrm{BMI}>25 \mathrm{~kg} / \mathrm{m}^{2} \quad(p=0.002)$. The underlying mechanism for this condition could be due to hyperinsulinaemia which causes marked reduction in uric acid excretion. ${ }^{20-21}$ 


\section{CONCLUSION}

Prevalence of hyperuricemia among hypertensive patients was high. In present study, hyperuricemia was common in male gender, older age, obese patients. It was also common among non-vegetarian patients and patients with longer duration of hypertension. Hyperuricemia was strongly associated with older age and higher BMI.

\section{RECOMMENDATIONS}

Prevalence of hyperuricemia was high among hypertensive patients. In clinical practices, measurement of serum uric level may help to identify associated condition in hypertensive patients. Proper management of hyperuricemia might help in controlling blood pressure and reducing cardiovascular morbidity and mortality.

\section{LIMITATIONS OF THE STUDY}

This is a cross-sectional hospital based study having small sample size, representing hypertensive patients from the eastern part of Nepal. It had not analyzed the effect of antihypertensive drugs in hypertensive patients. Confounding factors couldn't be controlled appropriately. The findings of this study, therefore, should be interpreted within context, and may not be generalized to the whole hypertensive patients.

\section{ACKNOWLEDGEMENTS}

We would like to express our gratitude to all the participants for participation in this study. We would like to thank department of Biochemistry for evaluation of serum uric acid level. We would like to express our sincere thanks to Mrs. Priyanka Pritam and Dr. Suresh Mehata in data interpretation, analysis and write up.

\section{CONFLICT OF INTEREST None}

\section{FINANCIAL DISCLOSURE}

None

12. Williams B, Mancia G, Spiering W, Agabiti Rosei E, Azizi M, Burnier M, Clement DL, Coca A, De Simone G, Dominiczak A, Kahan T. 2018 ESC/ESH Guidelines for the management of arterial hypertension: The Task Force for the management of arterial hypertension of the European Society of Cardiology (ESC) and the European Society of Hypertension (ESH). European heart journal. 2018 Sep 1;39(33): 3021-104. DOI: 10.1016/j.rec.2018.12.004

13. Bardin T, Richette P. Definition of hyperuricemia and gouty conditions. Current opinion in rheumatology. 2014 Mar 1;26(2):186-91. DOI: 10.1097/BOR.0000000000000028

14. Ndrepepa G. Uric acid and cardiovascular disease. Clinica chimica acta. 2018 Sep 1;484:150-63. DOI: 10.1016/j.cca.2018.05.046

15. Feig DI, Soletsky B, Johnson RJ. Effect of allopurinol on blood pressure of adolescents with newly diagnosed essential hypertension: a randomized trial. Jama. 2008 Aug 27;300(8):924-32. DOI: 10.1001/jama.300.8.924

16. Hu L, Huang X, You C, Li J, Hong K, Li P, Wu Y, Wu Q, Bao H, Cheng X. Prevalence and risk factors of prehypertension and hypertension in Southern China. PloS one. 2017 Jan 17;12(1):e0170238. DOI: 10.1371/journal.pone. 0170238

17. Ali N, Perveen R, Rahman S, Mahmood S, Rahman S, Islam S, Haque T, Sumon AH, Kathak RR, Molla NH, Islam F. Prevalence of hyperuricemia and the relationship between serum uric acid and obesity: A study on Bangladeshi adults. PLoS One. 2018 Nov 1;13(11):e0206850. DOI: 10.1371/journal.pone.0206850

18. Lin CS, Lee WL, Hung YJ, Lee DY, Chen KF, Chi WC, Chang SC. Prevalence of hyperuricemia and its association with antihypertensive treatment in hypertensive patients in Taiwan. International journal of cardiology. 2012 Apr 5;156(1):41-6. DOI: 10.1016/ j.ijcard. 2010.10.033

19. Matsuura F, Yamashita S, Nakamura T, Nishida M, Nozaki S, Funahashi T, Matsuzawa Y. Effect of visceral fat accumulation on uric acid metabolism in male obese subjects: visceral fat obesity is linked more closely to overproduction of uric acid than subcutaneous fat obesity. Metabolism. 1998 Aug 1;47(8):929-33. DOI: 10.1016/s00260495(98)90346-8

20. Čaušević A, Semiz S, Macić-Džanković A, Cico B, Dujić T, Malenica M, Bego T. Relevance of uric acid in progression of type 2 diabetes mellitus. Bosnian journal of basic medical sciences. 2010 Feb;10(1):54. DOI: 10.17305/bjbms.2010.2736

21. Emmerson B. Hyperlipidaemia in hyperuricaemia and gout. Annals of the rheumatic diseases. 1998 Sep 1;57(9):509-10. DOI: 10.1136/ ard.57.9.509 